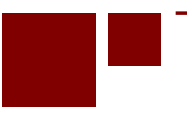

C E N T E R for RETIREMENT RE S E A R C H at BOSTON COLLEGE

\title{
SLOWED OR SIDELINED? THE EFFECT OF “NORMAL” COGNITIVE DECLINE ON JOB PERFORMANCE AMONG THE ELDERLY
}

\author{
Anek Belbase, Mashfiqur R. Khan, Alicia H. Munnell, and Anthony Webb \\ CRR WP 2015-12 \\ June 2015 \\ Center for Retirement Research at Boston College \\ Hovey House \\ 140 Commonwealth Ave \\ Chestnut Hill, MA 02467 \\ Tel: 617-552-1762 Fax: 617-552-0191 \\ http://crr.bc.edu
}

\begin{abstract}
All of the authors are affiliated with the Center for Retirement Research at Boston College (CRR). Anek Belbase is a research project manager at the CRR. Mashfiqur R. Khan is a former graduate research assistant at the CRR. Alicia H. Munnell is the Peter F. Drucker Professor of Management Sciences at Boston College's Carroll School of Management and director of the CRR. Anthony Webb is a senior research economist at the CRR. The research reported herein was performed pursuant to a grant from the U.S. Social Security Administration (SSA) funded as part of the Retirement Research Consortium. The opinions and conclusions expressed are solely those of the authors and do not represent the opinions or policy of SSA, any agency of the federal government, or Boston College. Neither the United States Government nor any agency thereof, nor any of their employees, makes any warranty, express or implied, or assumes any legal liability or responsibility for the accuracy, completeness, or usefulness of the contents of this report. Reference herein to any specific commercial product, process or service by trade name, trademark, manufacturer, or otherwise does not necessarily constitute or imply endorsement, recommendation or favoring by the United States Government or any agency thereof. The authors would like to thank Lauren Dahlin and Natalia Orlova for research assistance. All errors are their own.

(C) 2015, Anek Belbase, Mashfiqur R. Khan, Alicia H. Munnell, and Anthony Webb. All rights reserved. Short sections of text, not to exceed two paragraphs, may be quoted without explicit permission provided that full credit, including $(\subset$ notice, is given to the source.
\end{abstract}




\begin{abstract}
About the Center for Retirement Research
The Center for Retirement Research at Boston College, part of a consortium that includes parallel centers at the University of Michigan and the National Bureau of Economic Research, was established in 1998 through a grant from the Social Security Administration. The Center's mission is to produce first-class research and forge a strong link between the academic community and decision-makers in the public and private sectors around an issue of critical importance to the nation's future. To achieve this mission, the Center sponsors a wide variety of research projects, transmits new findings to a broad audience, trains new scholars, and broadens access to valuable data sources.
\end{abstract}

Center for Retirement Research at Boston College

Hovey House

140 Commonwealth Ave

Chestnut Hill, MA 02467

Tel: 617-552-1762 Fax: 617-552-0191

http://crr.bc.edu

Affiliated Institutions:

The Brookings Institution

Massachusetts Institute of Technology

Syracuse University

Urban Institute 


\begin{abstract}
This paper examines the relationship between age-related cognitive decline and three potential workplace outcomes: 1) coping with increased job difficulty; 2) shifting to a less cognitively demanding job; and 3) retiring early. It uses data from the Health and Retirement Study (HRS) and the $O^{*} N E T$ database. Critical components of the analysis are the metric used to measure cognitive decline, inclusion of cognitive reserve as an independent variable, and the use of overlapping 10-year observation windows. A key limitation is that the study cannot conclusively discern a causal relationship between cognitive decline and workforce exit.
\end{abstract}

The paper found that:

- About 10 percent of workers between the ages of 55 and 69 experienced steep cognitive decline over a 10-year period.

- Workers experiencing steep cognitive decline were more likely to "downshift" to a less demanding job or retire than workers experiencing no cognitive decline.

- Workers experiencing steep cognitive decline retired significantly earlier than planned, compared to workers who experienced no change in cognitive ability.

- Workers without cognitive reserves were more likely to exit the workforce and retire earlier than planned, compared to workers with cognitive reserves.

The policy implications of the findings are:

- Cognitive decline might prevent a significant minority of older individuals from working to their planned retirement ages, and thus should be considered when assessing reforms that incent delayed retirement.

- Policies that support “downshifting” to a cognitively less demanding job might help workers at risk of steep cognitive decline to remain in the labor force.

- Further research is needed to identify whether workers in specific occupations are more susceptible to age-related decline than others, and whether anything can be done to moderate the effect of age-related decline in work ability. 


\section{Introduction}

Twenty years of research on age-related cognitive change has cemented one fact: most people lose cognitive ability - just like they lose physical ability - well before the end of their working lives. The literature documents which cognitive abilities decline with age, how fast these abilities decline, how the brain physically changes with age, and how much people vary in the extent of decline they experience. Recent studies have also attempted to uncover the causes of cognitive decline and propose ways to mitigate or even reverse age-related cognitive change. But few studies have focused on the functional implications of cognitive decline, in particular the relationship between cognitive decline and work ability. As a result, it is not known the extent to which cognitive decline will be a barrier to working longer. As the number of white-collar workers continues to increase and retirement systems come under pressure to delay retirement benefits to offset improvements in longevity, any effect of age-related cognitive decline on work ability is likely to increase in importance. A better understanding of this topic will provide policymakers with a crucial piece of information currently unavailable.

The current study investigates the relationship between age-related cognitive decline and work ability. The study uses data from the Health and Retirement Study (HRS), a large, nationally representative longitudinal dataset of older workers and retirees in the United States, to test three hypotheses, workers who experience faster-than-average cognitive decline: 1) experience increased difficulty meeting job requirements; 2) are more likely to transition to a cognitively less demanding job; and 3) exit the workforce at higher rates and retire earlier than planned.

The remainder of this paper proceeds as follows: 1) a background section reviews the literature, highlighting important concepts and methodological issues related to the current study; 2) a methodology section describes the data sources, key variables, and econometric models used; 3) a results section summarizes findings; and 4) a conclusion section reports workers who experience faster-than-average cognitive decline are more likely to retire or transition to a cognitively less demanding job and also retire earlier than self-predicted. The study does not establish a causal relationship between cognitive decline and the likelihood of transitioning or retiring. 


\section{Background}

How Cognition Changes with Age and Why It Matters. For the majority of the population, "fluid” cognitive ability - the ability to acquire and use new information - starts to decline decades before retirement (e.g. Shaie, 1994; McArdle, Smith, and Willis, 2009; Salthouse, 2010; Schaie and Willis, 2010; Singh-Manoux, 2012). Age-related changes in brain structure, brain organization, performance on intelligence tests, and real-world functional ability support the notion that age-related cognitive decline is as real and inevitable as age-related physical decline. Brain volume, white matter, gray matter, and cortical thickness in areas related to memory, perception, attention, and decision-making all decline significantly in the last few decades of life (Nyberg et al. 2012). Studies of brain regions used to process specific types of information also show a significant difference in the activation patterns of old and young subjects (Reuter-Lorenz, 2002; Waiter, et al, 2008;). In other words, the brain’s neural "hardware” (its neurons) as well as its "software” (the way the neurons work together to respond to the environment) change with age.

While the existence of age-related decline in fluid cognition is not disputed, estimates of the timing of the onset of decline and rate of decline depend on methodology. Cross-sectional studies that do not control for cohort effects, such as better nutrition, higher educational attainment, and greater job-stimulation over time, show that cognitive decline starts in one's early 20s and continues at a linear rate until one's 80s (when most people experience a steep loss in ability) (Shaie, 1994, Salthouse 2012). ${ }^{1}$ Longitudinal studies show cognitive decline starting in one’s 50s and progressing at an increasing rate (Salthouse 2010 and 2013). But these studies understate the average rate of decline because individuals who experience rapid cognitive decline are more likely to die or cease to participate in the panel (attrition effects) and repeated testing leads to improved scores (practice effects). Recent studies have addressed methodological shortcomings of both approaches and the research consensus is that cognitive decline is detectable in one's 40s and progresses at an increasing rate, with significant decline evident by 60 (Singh-Manoux, 2012).

Performance in many real-world tasks - which require both fluid cognitive ability and acquired knowledge - has also been documented to decline with age despite increased work-

\footnotetext{
${ }^{1}$ This suggests a worker in the middle of the ability distribution at 20 could expect to be almost a full standard deviation below the mean in her 60s.
} 
related experience. Unlike fluid cognitive ability, acquired knowledge, also referred to as “crystallized intelligence,” continues to improve or remain stable well into one’s 70s (Salthouse, 2010). As a result, performance in the real world can continue to improve after fluid cognitive ability has peaked. Using a large administrative dataset of credit card and home equity loan information, Agrawal et al. (2009) show that the ability to make certain financial decisions which require a mix of experience and fluid cognitive ability — peaks around age 53 and then steadily declines. Similarly, some air traffic controllers in their 50s, with the help of experience, are able to perform at a level comparable to young controllers, but young controllers consistently outperform older recruits in training programs (where older workers do not have the advantage of acquired knowledge) (Nunes and Kramer, 2009; Salthouse, 2012). ${ }^{2}$ In other words, experience, which can be measured by tenure on the job, preserves work ability for job functions that do not change over time.

Age-related cognitive trends mask considerable individual variability with respect to the timing and extent of cognitive decline. A significant proportion of seniors enters retirement with well-preserved cognitive ability and maintains this ability well into retirement, while a small but still significant minority develops dementia. ${ }^{3}$ Habib et al. (2007) report that over 10 percent of respondents over age 70 in their sample of 1,500 adults meet the criteria for "successful cognitive aging.” In addition, Yaffe et al. (2009) report that 30 percent of the respondents in a dataset of 2,509 Americans aged 70-79 do not show cognitive decline over an 8-year period, further supporting the idea that a significant minority of adults maintain cognitive ability well into retirement. Brain scans of seniors with well-preserved cognitive abilities reveal that their brains lose less white and gray matter, maintain cortical thickness in important areas, and continue to activate regions in response to stimuli much like younger adults (summarized in Nyberg et al. 2012). In other words, seniors with preserved abilities do not just use experience to offset a reduction in cognitive ability - their brains appear to change less with age.

\footnotetext{
${ }^{2}$ Further support for the notion that acquired knowledge cannot completely offset declines in fluid cognitive ability come from expert studies that show peak performance, both in terms of the quantity and quality of work generated, occurs before the full retirement age across a variety of professions (Salthouse, 2012). Hambrick and Engle (2002) also show that domain knowledge and working memory (a component of fluid cognitive ability) have independent additive effects on domain-specific tasks.

${ }^{3}$ Several studies have identified four common trajectories of cognitive change: 1) little or no decline, 2) moderate, or "normal" decline, 3) faster-than-average decline that does not manifest itself as dementia, and 4) faster-thanaverage decline followed by a rapid onset of dementia (Yaffe et al. 2009; Ylikoski et al, 1999).
} 
A number of factors related to the preservation of cognitive ability in old age appear to be under one's control. Studies of cognitive differences between twins conclude that half of the inter-person difference in cognitive ability is attributable to genes, with the other half dependent on environmental factors (Finkel et al. 1998 and 2005; Nyberg et al. 2012). And these factors may be controllable: an intellectually stimulating job or volunteer activity, exercise, social engagement, and good nutrition all positively correlate with preserved cognitive ability (Fillit et al. 2002; Marquie et al. 2010; Yaffe et al. 2009). Notably, job stimulation and an engaged lifestyle predict preserved cognitive ability, which suggests a causal relationship between lifestyle and cognitive change (Lovden, Ghisletta, and Lindenberger, 2005; Small et al. 2012; Wilson et al. 2012). On the other hand, smoking, stress, diabetes, strokes, and a sedentary lifestyle (measured by hours watching television) are good predictors of faster-than-average decline in cognitive ability (Fillit et al, 2002; Waldstein, et al. 2005; Wang et al. 2005; Yaffe et al. 2009).

Work Ability and the Present Study. While understanding of age-related cognitive change has improved over the past two decades, the relationship between cognitive change and work ability is not well understood. It is not known how much work ability declines due to cognitive change, or whether workers respond to a decline in work ability - through disability retirement, transitions to easier occupations, or earlier retirement. Studies examining the relationship between work ability and age have focused on physically demanding jobs. The studies report earlier retirement ages and higher disability rates among workers employed in physically demanding occupations (Holden 1988; Lund et al. 2001; Karpansalo et al. 2002). But several European studies use a more comprehensive measure - the "work ability index" - to assess whether a combination of age-related physical and cognitive changes affect work ability (Avlund, Davidsen, and Schultz-Larsen, 1995; Ilmarinen and Tuomi, 1992; Ilmarinen, 2009). One such study of 6,257 Finnish civil servants reports that 30 percent of workers over age 45 lose a significant amount of work ability over an 11-year period. This loss is not restricted to blue-collar workers. Managers in the top quintile of work ability at the end of the study period retired five years later, on average, than those in the bottom quintile (Ilmarinen, 2009). In other words, the study finds that work ability declines with age among all occupations and that the change in ability results in a measurable change in retirement age. 
The current study does not attempt to measure the overall work ability of workers, but rather examines one important source of work ability: fluid cognition. Research suggests that fluid cognitive ability is one of the best predictors of work performance, with higher cognitive ability being associated with higher pay and a faster rate of growth in pay and occupational prestige (Salthouse, 2012). A loss in such a vital ingredient of work success can thus be expected to lead to a decline in one's ability to meet work demands. This study examines the relationship between age-related decline in fluid cognitive ability and the ability to meet job demands by modeling three potential outcomes: 1) increase in perceived job difficulty; 2) a transition to a less demanding job; and 3) a higher retirement rate and earlier-than-expected retirement. If cognitive change leads to less work ability, people who experience faster-thanaverage decline should report greater stress due to difficulty meeting job requirements. Such workers are also expected to be more likely to transition to less cognitively demanding jobs and retire earlier than expected.

This study cannot establish whether cognitive decline causes job stress, job transitions, or early retirement without addressing the possibility that cognitive decline is a result of, rather than a cause of, these labor market outcomes. For example, research shows that moving to a less cognitively demanding job can lead to faster-than-average cognitive decline (DeGrip et al, 2007; Then et al. 2013). Similarly, several studies have reported that early retirement leads to lower cognitive ability (Bonsang et al. 2012; Mazzona et al. 2012). An instrumental variable approach would be one way to establish causation but at the moment we have not been able to identify a suitable instrument. Despite this limitation, the project improves understanding of cognitive decline in the context of work ability, helping policymakers understand a potentially important constraint to future changes in the retirement system.

\section{Data and Methodology}

The Data. This paper uses data from the Health and Retirement Study (HRS), a nationally representative longitudinal household survey of older Americans. The original sample of 12,561 comprised individuals who were born 1931-41 or were the spouse of a participant in that birth cohort; individuals born 1942-47, 1948-53, and 1954-59 were added in 1998, 2004, and 2010. Participants are interviewed every two years; the latest data available are for 2012. The core sample used in this paper comprises 4,156 individuals who: 1) were both working for pay 
and age 50 or older in 1996, 1998, or 2000; 2) were age 75 or younger 10 years later (in 2006, 2008, or 2010); 3) had not received Disability Insurance during the 10-year window; 4) were not self-employed; and 5) had participated in at least three of the six interviews during the window.

The Cognition Variables. Two key variables required for this analysis are: 1) cognitive decline; and 2) cognitive reserve, which is the buffer between the cognition requirements of the occupation and the individual's level of cognition. A consistent measure of fluid cognition, available in the HRS since 1996, is the total word recall score - the sum of the immediate and delayed word recall scores. ${ }^{4}$ To measure word recall, respondents are read a list of 10 simple nouns and are then asked to immediately repeat as many as possible, in any order. After a fiveminute interval, they are then asked to repeat as many of the 10 words as possible. These two word recall variables measure episodic memory, which is strongly correlated with other measures of fluid cognitive ability and predicts problem-solving capacity among the elderly (McArdle et al., 2007; Gross et al. 2011).

In a cross section, cognition scores vary significantly, and these scores are correlated with age as well as education. As reported in prior studies, average cognitive scores decline with age, from 11.8 at age 57 to 9.8 at age 75 (Appendix A, Figure 1). ${ }^{5}$ Also consistent with the literature, greater educational attainment is associated with higher cognitive scores, with roughly six times as many workers with some college scoring more than 16 on the 20-point scale compared to workers with less than high school (Appendix A, Figure 2).

To measure changes in cognition for each individual, overlapping 10-year windows are created for each HRS participant, starting from $1996 .{ }^{6}$ For example, the first window is 19962006, the second is $1998-2008$, and so on. ${ }^{7}$ The following OLS regression is then estimated for each 10-year window for each individual:

\footnotetext{
${ }^{4}$ The HRS also asks questions that measure various aspects of cognition, including episodic memory, intactness of mental status, numerical reasoning, broad numeracy, and vocabulary (McArdle, Smith, and Willis, 2009).

${ }^{5}$ This rate of change represents a decline of 0.6 of a standard deviation of the pooled cross section scores over an 18-year period, which is consistent with the .02 to .04 standard deviation annual rate of decline reported by Shae (1994) and Salthouse (2012).

${ }^{6}$ A statistically detectable change in cognitive ability is required for the analysis attempted in this paper to be meaningful, and cognitive ability is expected to decline by at least 0.2 standard deviations of the ability-distribution in a 10-year period; see Shae (1994) and Salthouse (2012).

${ }^{7}$ An alternative would have been to estimate a single slope for each individual, using all available data. But the level of significance of the coefficient would vary with the length of the observation period.
} 


$$
\text { Cognition }_{i j t}=\alpha_{i j}+\beta_{i j} * \text { Age }_{i j t}+\varepsilon_{i j t}
$$

The coefficient $\beta_{i j}$ measures the annual rate of change in cognition of individual $i$ during the time window $j$. Each person can have as many as three coefficients because a person can be in the sample for more than one overlapping 10 -year period. ${ }^{8}$ Based on their $\boldsymbol{\beta}_{\bar{y}}$ coefficients, we classify individuals over each 10-year period as having experienced a steep decline in cognition, $\beta_{i j} \leq-0.5$; a moderate decline, $-.05<\beta_{i j}<-0.15$; more or less no change, $-0.15 \leq \beta_{i j} \leq 0.1$; and an improvement, $0.1<\beta_{i j}{ }^{9}{ }^{9}$ Approximately 12 percent, 30 percent, 30 percent, and 28 percent of individuals fall into the above categories, respectively.

In addition to cognitive ability and cognitive change, cognitive reserve - the difference between a worker's cognitive ability and his occupation-related cognitive requirements is an important variable used in the analysis, because workers with large reserves or "buffers" are expected to respond less to a decline in their cognitive abilities (Barulli and Stern, 2013). To measure occupation-related cognitive requirements, the HRS is merged with restricted Social Security Administration (SSA) administrative occupation data and the 2010 version of the Occupational Information Network (O*NET) database. The O*NET contains information on 21 cognitive abilities associated with 812 U.S. occupations. ${ }^{10}$ The O*NET surveys jobholders, occupational analysts, and occupational experts to measure the importance and required level of each ability for each occupation. These two measures of job-ability requirements - level and importance - are combined and aggregated across the 21 cognitive abilities to create a single cognitive demand index for each occupation. The index varies from 2.8 to 15.8. The cognitive demand index is merged with the HRS by creating an occupation code crosswalk between the 1998, 2002, and 2010 census codes (used in different waves of the HRS restricted data) and the 2010 Standard Occupational Codes (SOC) used in the O*NET. Appendix A, Figure 3 shows a positive relationship between this cognitive demand index and average cognitive scores with a

\footnotetext{
${ }^{8}$ The functional form of the above regression equation imposes the assumption that the rate of decline in our measure of cognition is linear with age. In common with other researchers, we use test performance as a proxy for underlying cognitive ability. In reality, changes in cognitive ability may be discontinuous, perhaps triggered by health or other shocks.

${ }^{9}$ Dividing cognitive change into these four buckets assumes the effect of cognitive change on labor market outcomes is non-linear. This approach is consistent with the approaches taken by Ylikoski, et al (1999), and Yaffe, et al (2009) to classify cognitive change, as well as Ilmarinen (2009) to categorize changes in work-ability.

${ }^{10}$ The 2010 O*NET uses the 2010 Standard Occupational Classification system, which catalogues 812 distinct occupations.
} 
correlation coefficient of 0.21 , which is significant at the 1 -percent level. The correlation coefficient between the cognitive demand index and average cognitive scores is 0.25 for men and 0.21 for women.

Cognitive reserve for each individual is calculated as the difference between the occupation-related cognitive requirements and the individual's level of cognitive ability as measured by his total word recall score. First, each individual's baseline cognitive score is converted to a percentile rank (based on where that score stands in the distribution of all scores for the sample). Then, each occupation is similarly assigned a cognitive demand percentile (based on where the cognitive demand index score for the occupation stands within the distribution of scores for all occupations in the sample). Next, individuals are assigned to a cognitive reserve condition based on the difference between their cognitive score percentile and the cognitive demand percentile for their occupation at baseline. ${ }^{11}$

Other important variables used in the analysis include controls for job tenure and practice effect. $^{12}$ Tenure is hypothesized to compensate for the loss of fluid intelligence through the acquisition of crystallized intelligence gained on the job, and is coded as a categorical variable representing less than 5 years of tenure, 5-15 years, and more than 15 years. ${ }^{13}$ Since repeated test-taking is expected to inflate cognitive scores (Wilson, et al, 2006), we control for the number of times the test has been taken. The analysis also controls for the effects of gender, race, educational attainment, performing physically demanding work, and changes in wealth and health.

Empirical Strategy. With measures of the rate of decline in cognition and cognitive reserve in hand, we consider three outcomes: 1) an increase in self-reported work-difficulty; 2) a

${ }^{11}$ If a person falls into top tercile in cognition and his/her job ranks in the bottom tercile in cognitive requirement, then that person is classified as high positive reserve; if a person falls in bottom tercile in cognition and his/her job ranks in the top tercile in cognitive requirement, then that person is classified as high negative reserve; if the tercilerank in cognition minus the tercile-rank in job cognitive requirement is +1 , then that person is classified as moderate positive reserve; if the tercile-rank in cognition minus the tercile-rank in job cognitive requirement is -1 , then that person is classified as moderate negative reserve; if a person falls into the tercile-rank in both cognition and job requirement, then that person is classified as breakeven.

${ }^{12}$ Attrition is presented as a potentially important variable affecting longitudinal measures of cognitive change. This study does not control for the effect of attrition on the relationship between cognitive decline and labor force outcomes but expects this omission to potentially bias results in the direction of understating the relationship between cognitive decline and workforce exit (Salthouse, 2013).

${ }^{13}$ The effect of tenure on occupational outcomes is expected to be nonlinear, with longer tenure associated with a lower probability of job change, higher job satisfaction, and an actual retirement age surpassing expected retirement age. 
greater 10-year risk of moving to a job with a lower cognitive requirement or retirement; and 3) an actual retirement age that is less than the expected retirement age reported at the start of the window. The study classifies individuals as experiencing increased job stress if they previously did not report that their job has become more difficult, and report that their job has become more difficult at the last interview during the 10 -year window. ${ }^{14}$ A potential concern is that individuals experiencing the greatest increase in job stress may retire. For workers who exit the workforce, we include self-reported job difficulty from the latest wave at which they were working for pay. A detailed account of the methodology used to code each outcome variable can be found in Appendix C.

We estimate a multinomial logit model that seeks to explain the probability of observing that an individual retires or moves to a job with lower cognitive demands during the 10-year window, relative to the base case of remaining in the job held at the start of the window or switching to a job with the same or higher cognitive demands. Ignoring for now the possibility of correlations of the error term across observations, the probability that a particular $y_{i k}$ is observed, conditional on observables $\boldsymbol{x}_{\boldsymbol{i}}$, can be expressed as:

$$
\operatorname{Pr}\left[y_{i k}=j \mid x_{i}\right]=\frac{\exp \left(x_{i}^{\prime} \beta_{j}\right)}{1+\sum_{j=1}^{k} \exp \left(\dot{x}_{i}^{\prime} \beta_{j}\right)}
$$

where the matrix $x$ includes the annual rate of cognitive decline over the 10-year window, baseline cognitive reserve, time invariant controls such as educational attainment, and time varying controls such as health shocks. As is usual in the multinomial formulation, coefficients are identified for $k-1$ of the outcomes, relative to an arbitrarily chosen base case, with a coefficient of less than one indicating $x$ has a negative relationship with the dependent variable and a coefficient of more than one indicating a positive relationship with the dependent variable.

For models with a binary dependent variable, we estimate the following probit model and report probit marginal effects:

$$
\operatorname{Pr}\left[y_{i k}=1 \mid x_{i}\right]=\Phi\left(x_{i}^{\prime} \beta_{j}\right)
$$

\footnotetext{
${ }^{14}$ Subjective reports of job difficulty are likely to be influenced by job-specific and time-specific variables this study cannot control for (for example, a demanding boss or a temporary, unpleasant work assignment). Nonetheless it is included in the analysis as a potential channel through which cognitive decline is manifested in the workplace.
} 
where $\Phi$ is the cumulative normal distribution. The marginal effects report the association between a one unit change in a particular $\boldsymbol{x}$ variable on the probability of the occurrence, holding all other $\boldsymbol{x}$ variables constant at their means. When comparing actual with anticipated retirement ages, we estimate an OLS model in which the dependent variable is the actual minus anticipated retirement age. ${ }^{15}$

\section{Results}

Regression results suggest cognitive decline might limit the ability of some workers to remain in the labor force as long as planned. First, controlling for age, cognitive reserve, tenure, and other variables described earlier, workers experiencing steep cognitive decline are at significantly higher risk of retiring within a 10-year observation window than workers experiencing a moderate decline or an improvement in cognitive ability. Second, workers experiencing steep cognitive decline are also more likely to "downshift” to a cognitively less demanding job and retire compared to workers who do not experience cognitive change. Finally, workers without cognitive reserves are also at higher risk of retirement in the observation window and retire significantly earlier than planned compared to workers with cognitive reserves.

Moving to a job with a lower cognitive requirement. Table 1 shows the relative risk ratios (RRR) of workers moving to a cognitively less demanding job or retiring, as opposed to continuing to work at a job with the same level of cognitive difficulty, contingent on their rate of cognitive decline (see Appendix B, Table 1 for regression results with all variables in the model). RRR is a transformation of the estimated logit coefficient and captures the marginal effect of the covariate on the likelihood of a particular transition occurring relative to the likelihood of the base outcome (staying in the same job). If the RRR takes a value equal to 1 , then the right-hand side variable does not alter the likelihood of that particular job transition occurring relative to staying in the job. If the RRR takes a value smaller than 1 , then the variable reduces the likelihood of the job transition occurring relative to staying in the job by the percentage of RRR - 1. If the RRR takes a value greater than 1 , it raises the likelihood relative to staying in the job.

\footnotetext{
${ }^{15}$ We adjust for censoring of data on actual retirement ages thus retirements of workers who retire earlier than planned are more likely to be observed.
} 
Among all workers in the sample, 48.1 percent retire in the 10-year observation window and 11.6 percent move to a cognitively less demanding job. Controlling for cognitive reserve, tenure, and other factors described earlier, workers experiencing steep cognitive decline are 79 percent more likely to retire in the 10-year window compared to workers experiencing low to no decline (statistically significant at $\mathrm{p}<.01$ ). Steep cognitive decline is associated with approximately double the likelihood of moving to a cognitively less demanding job during the 10-year window.

Table 1. Relative Risk of Downshifting and Retirement, by Rate of Cognitive Change (Base: Low to No Cognitive Change)

\begin{tabular}{lcl}
\hline & Downshift & Retire \\
\hline Steep decline & $2.071^{* *}$ & $1.794^{* *}$ \\
Moderate decline & 0.860 & 1.141 \\
Improvement & 0.961 & 1.006 \\
\hline
\end{tabular}

Notes: ${ }^{*} \mathrm{p}<0.10,{ }^{* *} \mathrm{p}<0.05,{ }^{* * *} \mathrm{p}<0.01$. Relative Risk Ratios are reported.

Source: Authors’ estimates using Health and Retirement Study, 1996-2010 waves.

Cognitive reserve is also related to the probability of downshifts and retirement during the 10-year observation window. Compared to individuals for whom cognitive ability matches the cognitive demands for their occupation, individuals with high positive reserve (more ability than is required) are 69 percent less likely to move to a less cognitively demanding job in the 10year window $(100 *(1.0$ - 0.314)) while individuals with high negative cognitive reserves (less ability than required) are twice as likely to retire during the 10-year window (Table 2).

Table 2. Relative Risk of Downshifting and Retirement, by Amount of Cognitive Reserve (Base: Cognitive Demands and Cognitive Ability Are Break-Even)

\begin{tabular}{lcl}
\hline & Downshift & Retire \\
\hline High positive & $0.314^{*}$ & 1.240 \\
Moderate positive & 0.767 & 1.162 \\
Moderate negative & 1.338 & 1.459 \\
High negative & 1.230 & $2.086^{* *}$ \\
\hline
\end{tabular}

Notes: * $\mathrm{p}<0.10$, ** $\mathrm{p}<0.05, * * * \mathrm{p}<0.01$. Relative Risk Ratios are reported.

Source: Authors' estimates using Health and Retirement Study, 1996-2010 waves. 
Reporting that an existing job has become more stressful. Table 3 shows the marginal effect ${ }^{16}$ of cognitive change on whether a job is classified as "more difficult than before." A statistically significant relationship is not found between cognitive change and this measure of job difficulty after controlling for cognitive reserve, tenure, and health shocks (which do vary in a statistically significant manner with this outcome). ${ }^{17}$ Regression results with the full set of variables are reported in Appendix B, Table 2).

Table 3. Change in Job Difficulty, by Rate of Cognitive Change

\begin{tabular}{lc}
\hline & Job more difficult \\
\hline Steep decline & 0.037 \\
Moderate decline & -0.018 \\
Improvement & 0.019 \\
\hline
\end{tabular}

Notes: * $\mathrm{p}<0.10, * * \mathrm{p}<0.05, * * * \mathrm{p}<0.01$. Average Marginal Effects (AME) are reported for Probit models. Source: Authors’ estimates using Health and Retirement Study, 1996-2010 waves.

Deviation of actual from expected retirement age. Table 4 shows the difference between the actual retirement age and the expected retirement age reported at the start of each observation window. Both workers experiencing steep cognitive decline and workers experiencing cognitive improvement show a statistically significant tendency to retire earlier than projected compared to workers with no change in cognitive ability. However, steep cognitive decline is associated with the largest gap between actual and expected retirement age: 2.4 years earlier than expected among "steep decliners" vs. 1.2 years earlier than expected among “improvers.” When voluntary retirement is excluded from the analysis, only steep decline is associated with earlier-thanplanned retirement. This finding is consistent with the idea that individuals who experience improved cognitive ability retire earlier than planned for different reasons than individuals who experience a steep decline in cognitive ability. Regression results with the full set of variables can be found in Appendix B, Table 3.

\footnotetext{
${ }^{16}$ The marginal effect using a probit regression reports the expected change in the probability of an event (e.g. reporting that one's job is stressful) holding all other variables at their means.

${ }^{17}$ The sign and magnitude of the coefficients are consistent with the hypothesis that individuals experiencing steep decline also experience greater work difficulty but the results are not statistically significant.
} 
Table 4. Difference Between Expected and Actual Retirement Age, by Rate of Cognitive Change

\begin{tabular}{lc}
\hline & Years retired earlier than planned \\
\hline Steep decline & $2.434^{* * *}$ \\
Moderate decline & 0.530 \\
Improvement & $1.215^{* * *}$ \\
\hline
\end{tabular}

Notes: ${ }^{*} \mathrm{p}<0.10, * * \mathrm{p}<0.05$, $* * * \mathrm{p}<0.01$. The regressions include full set of age dummies.

Source: Authors' estimates using Health and Retirement Study, 1996-2010 waves.

Cognitive reserve is also related to the difference between the expected and actual retirement ages. Workers without cognitive reserves (i.e. those with less cognitive ability than required) retire earlier than planned, whereas workers with cognitive reserves (greater cognitive ability than required) do not show a statistically significant difference between their expected and actual retirement ages. The degree of the mismatch between job requirements and cognitive ability also matters among workers without cognitive reserves: those with the largest shortfall between job requirements and cognitive ability retired, on average, 2.2 years earlier than planned, whereas those with a more modest shortfall in cognitive ability retired, on average, 1.4 years earlier than planned (Table 5).

Table 5. Difference Between Expected and Actual Retirement Age, by Amount of Cognitive Reserve

\begin{tabular}{lc}
\hline & Years retired earlier than planned \\
\hline High positive & 0.780 \\
Moderate positive & 0.615 \\
Moderate negative & $-1.362^{* *}$ \\
High negative & $-2.213^{* *}$ \\
\hline
\end{tabular}

Notes: ${ }^{*} \mathrm{p}<0.10,{ }^{* *} \mathrm{p}<0.05,{ }^{* * *} \mathrm{p}<0.01$. Relative Risk Ratios are reported.

Source: Authors' estimates using Health and Retirement Study, 1996-2010 waves.

\section{Conclusion}

A rich body of literature describes age-related decline in fluid cognitive ability, while a small but growing list of studies examines ways in which decline in cognitive ability affects performance in real-world tasks. The current study contributes to the latter by examining the relationship between decline in cognitive ability and the ability to delay retirement. It finds 
evidence supporting the notion that a steep decline in cognitive ability, observed among 10 percent of the sample, is associated with a higher probability of "downshifting" to a less demanding job and retiring from the workforce. It also associates steep cognitive decline with retiring earlier than expected. Further evidence is presented supporting the idea that workers without cognitive reserves are also more likely to retire and to retire earlier than expected, compared to workers who have cognitive reserves.

The study has important limitations. It does not establish whether cognitive decline causes a loss of work ability that prevents workers from working up to their planned retirement age - an important consideration in light of research that suggests retirement can cause cognitive decline. It also measures only one type of cognitive ability and does not take into account other ways in which cognitive abilities contribute to work performance. Further research is needed to shed light on these and other issues raised by the current study.

The study has several policy implications. First, new evidence suggests that cognitive decline might be a factor in limiting the extent to which retirement can be delayed, especially among workers with low cognitive reserves. Proposals to further increase the Full Retirement Age should consider this finding when assessing the effect of legislation on retirement timing. The study also suggests "downshifting” to a cognitively less demanding job might be a viable way to stay in the labor force for people at risk of steep cognitive decline. Finally, the results suggest age-related decline in mental capacity might have a differential impact on workers based on their occupations and individual rates of decline, supporting the need for further research into the interaction between age-related changes in work ability and work requirements for specific occupations. 


\section{References}

Agarwal, S., Driscoll, J. C., Gabaix, X., and Laibson, D. 2007. “The Age of Reason: Financial Decisions Over the Lifecycle.” Working Paper 13191. Cambridge, MA: National Bureau of Economic Research.

Avlund, K., Davidsen, M., andSchultz-Larsen, K. 1995. "Changes in Functional Ability from Ages 70 to 75. A Danish Longitudinal Study.” Journal of Aging and Health 7(2): 254282.

Avolio, B. J., and Waldman, D. A. 1990. “An Examination of Age and Cognitive Test Performance Across Job Complexity and Occupational Types.” Journal of Applied Psychology 75(1): 43-50.

Barulli, D., and Stern, Y. 2013. “Efficiency, Capacity, Compensation, Maintenance, Plasticity: Emerging Concepts in Cognitive Reserve.” Trends in Cognitive Sciences 17(10): 502509.

Bernheim, B. D., and Levin, L. 1989. “Social Security and Personal Saving: An Analysis of Expectations.” The American Economic Review 79(2): 97-102.

Bonsang, E., Adam, S., and Perelman, S. 2012. "Does Retirement Affect Cognitive Functioning?” Journal of Health Economics 31(3): 490-501.

De Grip, A., Bosma, H., Willems, D., and Van Boxtel, M. 2007. "Job-Worker Mismatch and Cognitive Decline.” Oxford Economic Papers 60(2008): 237-253.

Disney, R., and Tanner, S. 1999. "What Can We Learn From Retirement Expectations Data?” Working Paper W99/17. London, U.K.: The Institute for Fiscal Studies.

Fillit, H. M., Butler, R. N., O’Connell, A. W., Albert, M. S., Birren, J. E., Cotman, C. W., and Tully, T. 2002. “Achieving and Maintaining Cognitive Vitality with Aging.” Mayo Clinic Proceedings 77(7): 681-696.

Finkel, D., Reynolds, C. A., McArdle, J. J., and Pedersen, N. L. 2005. “The Longitudinal Relationship Between Processing Speed and Cognitive Ability: Genetic and Environmental Influences.” Behavioral Genetics 35(5): 535-549.

Finkel, D., Pedersen, N. L., Plomin, R., and McClearn, G. E. 1998. "Longitudinal and CrossSectional Twin Data on Cognitive Abilities in Adulthood: The Swedish Adoption/Twin Study of Aging.” Developmental Psychology 34(6): 1400-1413.

Gross, A. L., Rebok, G. W., Unverzagt, F. W., Willis, S. L., and Brandt, J. 2011. "Word List Memory Predicts Everyday Function and Problem-Solving in the Elderly: Results from the ACTIVE Cognitive Intervention Trial.” Aging, Neuropsychology, and Cognition 18(2): 129-146. 
Habib, R., Nyberg, L., and Nilsson, L. G. 2007. “Cognitive and Non-Cognitive Factors Contributing to the Longitudinal Identification of Successful Older Adults in the Betula Study." Aging, Neuropsychology, and Cognition 14(3): 257-273.

Hambrick, D. Z., and Engle, R. W. 2002. "Effects of Domain Knowledge, Working Memory Capacity, and Age on Cognitive Performance: An Investigation of the Knowledge-IsPower Hypothesis.” Cognitive Psychology 44(4): 339-387.

Holden, K. C. 1988. "Physically Demanding Occupations, Health, and Work after Retirement: Findings from the New Beneficiary Survey.” Social Security Bulletin 51(11): 3-15.

Ilmarinen, J. 2009. "Work Ability - A Comprehensive Concept for Occupational Health Research and Prevention.” Scandinavian Journal of Work, Environment \& Health 35(1): $1-5$.

Ilmarinen, J. and Tuomi, K. 1992. "Work Ability of Aging Workers.” Scandinavian Journal of Work, Environment \& Health 18(2): 8-10.

Karpansalo, M., Manninen, P., Lakka, T. A., Kauhanen, J., Rauramaa, R., and Salonen, J. T. 2002. "Physical Workload and Risk of Early Retirement: Prospective Population-Based Study Among Middle-Aged Men.” Journal of Occupational and Environmental Medicine 44(10): 930-939.

Kramer, A. F., Erickson, K. I., and Colcombe, S. J. 2006. "Exercise, Cognition, and the Aging Brain.” Journal of Applied Physiology 101(4): 1237-1242.

Loughran, D., Panis, C., Hurd, M., and Reti, M. 2001. “Retirement Planning.” RAND manuscript. Santa Monica, CA: RAND Corporation.

Lövdén, M., Ghisletta, P., and Lindenberger, U. 2005. "Social Participation Attenuates Decline in Perceptual Speed in Old and Very Old Age.” Psychology and Aging 20(3): 423-434.

Lund, T., Iversen, L., and Poulsen, K. B. 2001. "Work Environment Factors, Health, Lifestyle and Marital Status as Predictors of Job Change and Early Retirement in Physically Heavy Occupations.” American Journal of Industrial Medicine 40(2): 161-169.

Marquie, J. C., Duarte, L. R., Bessieres, P., Dalm, C., Gentil, C., and Ruidavets, J. B. 2010. "Higher Mental Stimulation at Work Is Associated with Improved Cognitive Functioning in Both Young and Older Workers.” Ergonomics 53(11): 1287-1301.

Mazzonna, F. and Peracchi, F. 2012. “Ageing, Cognitive Abilities and Retirement.” European Economic Review 56(4): 691-710.

McArdle, J. J., Fisher, G. G., and Kadlec, K. M. 2007. “Latent Variable Analyses of Age Trends of Cognition in the Health and Retirement Study, 1992-2004.” Psychology and Aging 22(3): 525-545.

McArdle, J. J., Smith, J. P., and Willis, R. 2009. “Cognition and Economic Outcomes in the Health and Retirement Survey.” Working Paper 15266. Cambridge, MA: National Bureau of Economic Research. 
Nunes, A., and Kramer, A. F. 2009. "Experience-Based Mitigation of Age-Related Performance Declines: Evidence from Air Traffic Control.” Journal of Experimental Psychology Applied 15(1): 12-24.

Nyberg, L., Lövdén, M., Riklund, K., Lindenberger, U., and Bäckman, L. 2012. “Memory Aging and Brain Maintenance.” Trends in Cognitive Sciences 16(5): 292-305.

Reuter-Lorenz, P. A. 2002. “New Visions of the Aging Mind and Brain.” Trends in Cognitive Sciences 6(9): 394-400.

Salthouse, T. A. 1998. "Independence of Age-Related Influences on Cognitive Abilities Across the Life Span.” Developmental Psychology 34(5): 851-864.

Salthouse, T. A. 2009. Major Issues in Cognitive Aging. Oxford, UK: Oxford University Press.

Salthouse, T. A. 2010. "Does the Meaning of Neurocognitive Change Change with Age?” Neuropsychology 24(2): 273-278.

Salthouse, T. A. 2012. "Does the Direction and Magnitude of Cognitive Change Depend on Initial Level of Ability?” Intelligence 40(4): 352-361.

Salthouse, T. A. 2012. “Are Individual Differences in Rates of Aging Greater at Older Ages?” Neurobiology of Aging 33(10): 2373-2381.

Salthouse, T. A. 2012. “Consequences of Age-Related Cognitive Declines.” Annual Review of Psychology 63: 201-206.

Salthouse, T. A. 2013. "Effects of Age and Ability on Components of Cognitive Change.” Intelligence 41(5): 501-511.

Salthouse, T. A. 2013. "Selectivity of Attrition in Longitudinal Studies of Cognitive Functioning.” The Journals of Gerontology Series B: Psychological Sciences and Social Sciences 69(4): 567-574.

Salthouse, T. A. 2013. "Within-Cohort Age-Related Differences in Cognitive Functioning.” Psychological Science 24(2): 123-30.

Schaie, K. W. 1994. “The Course of Adult Intellectual Development.” American Psychologist 49(4): 304-313.

Schaie, K. W., \& Willis, S. L. 2010. “The Seattle Longitudinal Study of Adult Cognitive Development.” ISSBD Bulletin 57(1): 24-29.

Singh-Manoux, A., Kivimaki, M., Glymour, M. M., Elbaz, A., Berr, C., Ebmeier, K. P., and Dugravot, A. 2012. "Timing of Onset of Cognitive Decline: Results from Whitehall II Prospective Cohort Study.” BMJ 344: d7622.

Small, B. J., Dixon, R. A., McArdle, J. J., and Grimm, K. J. 2012. “Do Changes in Lifestyle Engagement Moderate Cognitive Decline in Normal Aging? Evidence from the Victoria Longitudinal Study.” Neuropsychology 26(2): 144-155. 
Tabbarah, M., Crimmins, E. M., and Seeman, T. E. 2002. “The Relationship Between Cognitive and Physical Performance MacArthur Studies of Successful Aging.” The Journals of Gerontology Series A: Biological Sciences and Medical Sciences 57(4): M228-M235.

Then, F. S., Luck, T., Luppa, M., Thinschmidt, M., Deckert, S., Nieuwenhuijsen, K., and RiedelHeller, S. G. 2014. "Systematic Review of the Effect of the Psychosocial Working Environment on Cognition and Dementia.” Occupational and Environmental Medicine 71(5): 358-365.

Van den Berg, T., Elders, L., de Zwart, B., and Burdorf, A. 2008. “The Effects of Work-Related and Individual Factors on the Work Ability Index: A Systematic Review.” Occupational and Environmental Medicine 66(4): 211-20.

Waiter, G. D., Fox, H. C., Murray, A. D., Starr, J. M., Staff, R. T., Bourne, V. J., and Deary, I. J. 2008. "Is Retaining the Youthful Functional Anatomy Underlying Speed of Information Processing a Signature of Successful Cognitive Ageing? An Event-Related FMRI Study of Inspection Time Performance.” Neuroimage 41(2): 581-595.

Waldstein, S. R., Giggey, P. P., Thayer, J. F., and Zonderman, A. B. 2005. "Nonlinear Relations of Blood Pressure to Cognitive Function the Baltimore Longitudinal Study of Aging.” Hypertension 45(3): 374-379.

Wang, J. Y. J., Zhou, D. H. D., Li, J., Zhang, M., Deng, J., Tang, M., and Chen, M. 2006. "Leisure Activity and Risk of Cognitive Impairment: The Chongqing Aging Study.” Neurology 66(6): 911-913.

Wilson, R. S., Li, Y., Bienias, L., and Bennett, D. A. 2006. “Cognitive Decline in Old Age: Separating Retest Effects from the Effects of Growing Older.” Psychology and Aging 21(4): 774-789.

Wilson, R. S., Segawa, E., Boyle, P. A., and Bennett, D.A. 2012. “Influence of Late-Life Cognitive Activity on Cognitive Health.” Neurology 78(15): 1123-1129.

Van Gelder, B. M., Tijhuis, M. A. R., Kalmijn, S., Giampaoli, S., Nissinen, A., and Kromhout, D. 2004. "Physical Activity in Relation to Cognitive Decline in Elderly Men: The FINE Study.” Neurology 63(12): 2316-2321.

Yaffe, K., Fiocco, A. J., Lindquist, K., Vittinghoff, E., Simonsick, E. M., Newman, A. B., and Harris, T. B. 2009. "Predictors of Maintaining Cognitive Function in Older Adults: The Health ABC Study.” Neurology 72(23): 2029-2035.

Ylikoski, R., Ylikoski, A., Keskivaara, P., Tilvis, R., Sulkava, R., and Erkinjuntti, T. 1999. "Heterogeneity of Cognitive Profiles in Aging: Successful Aging, Normal Aging, and Individuals at Risk for Cognitive Decline.” European Journal of Neurology 6(6): 645652. 


\section{Appendix A: Figures}

Figure 1. Relationship between Cognitive Score and Age

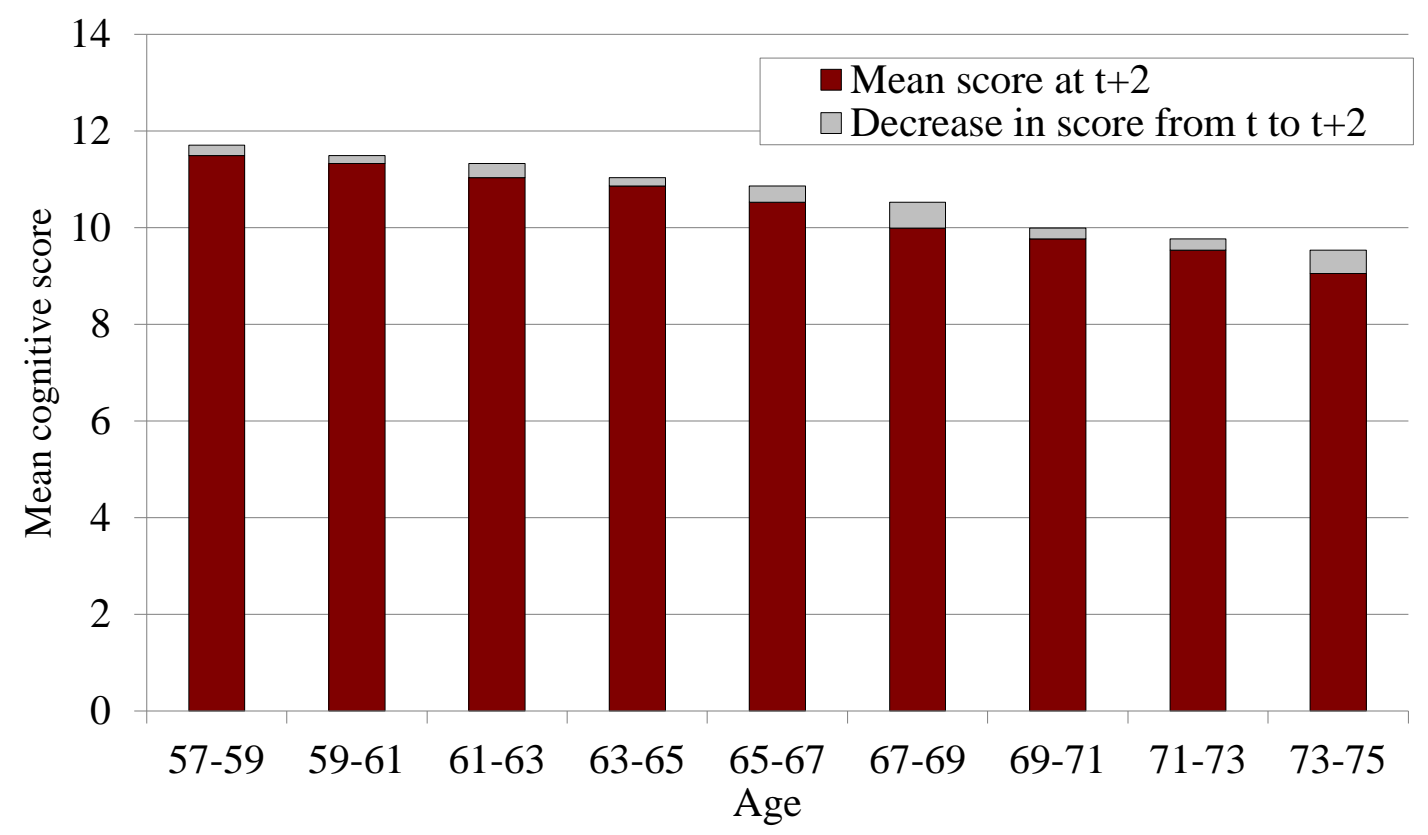

Notes: Authors' calculations.. The height of the first column shows the average score of participants age 55 who were also surveyed at age 57. The solid section of the bar shows their average score at 57, and the outlined section the average decline from 55 to 57 . The second column shows corresponding scores at 57 and 59 . The total decline in cognitive score from 55 to 75 equals two, the sum of the heights of the outlined sections, approximately 0.6 of a standard deviation of the pooled cross section scores 
Figure 2. Relationship Between Cognitive Score and Educational Attainment

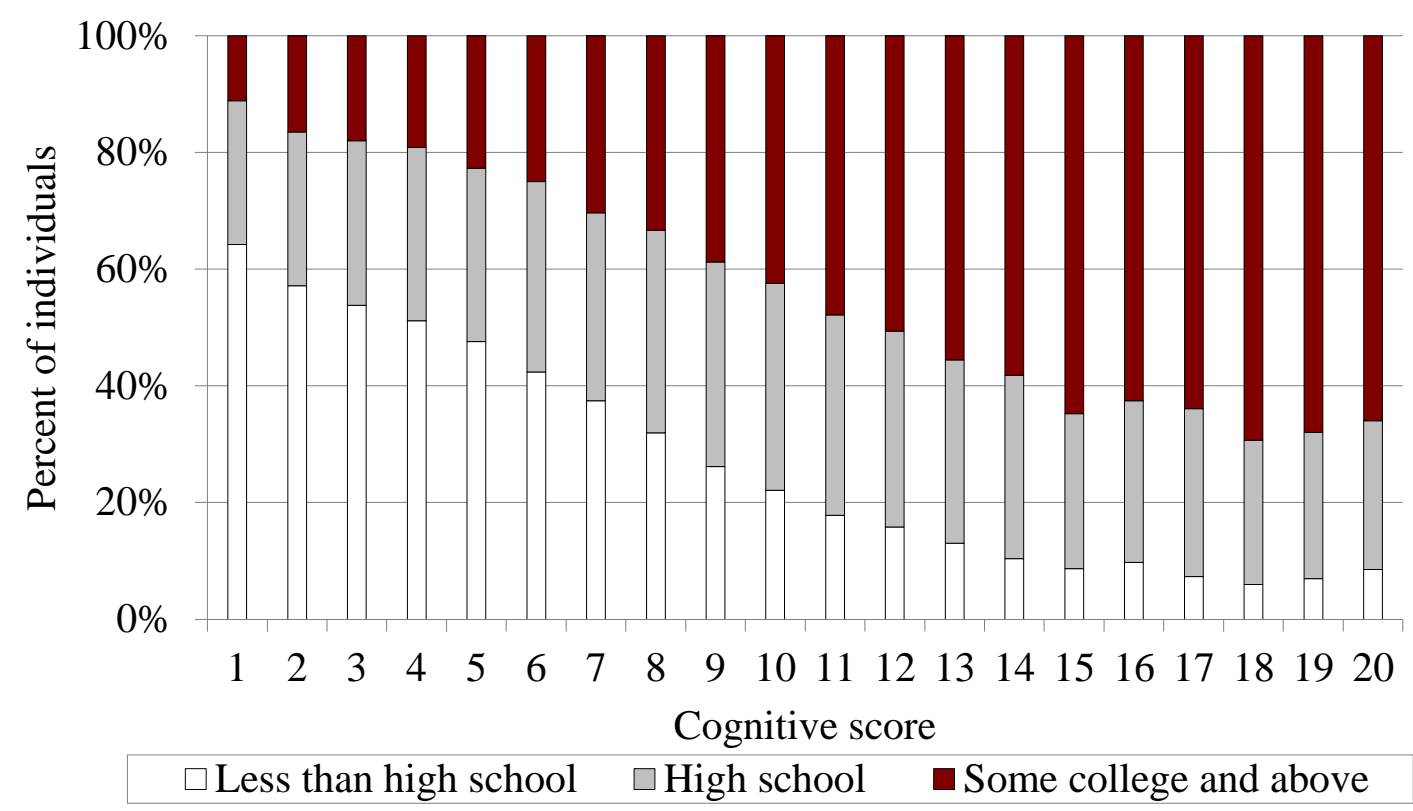

Source: Authors' calculations.

Figure 3: Relationship Between Cognitive Score and Occupational Cognitive Requirement

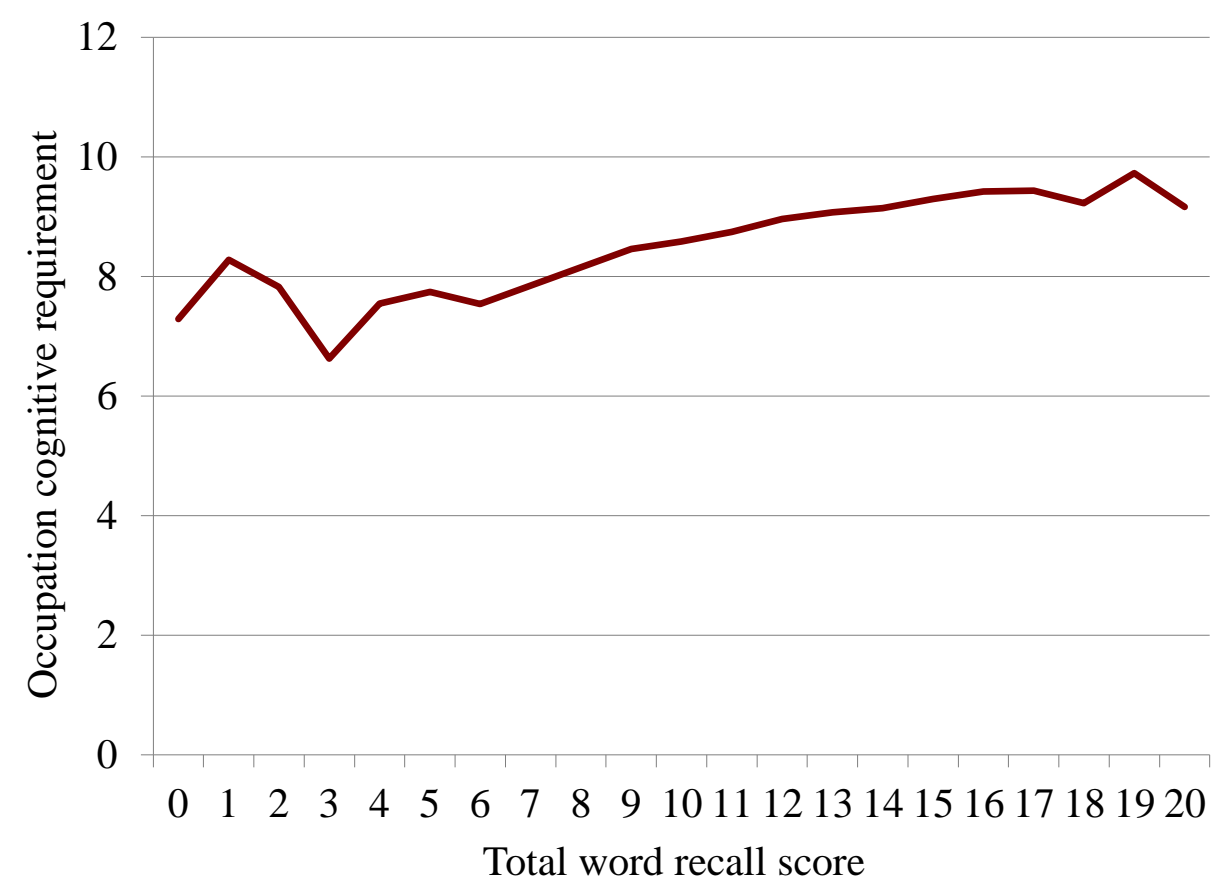

Source: Authors’ calculations. 


\section{Appendix B: Full Regression Results}

Table 1. Relative Risk of Downshifting and Retirement (Compared to Staying in Same Occupation or Moving to a More Demanding Occupation)

\begin{tabular}{|c|c|c|}
\hline & Low cognitive job & Retirement \\
\hline \multicolumn{3}{|l|}{ Cognitive change categories } \\
\hline \multirow[t]{2}{*}{ Steep decline } & $2.071^{* *}$ & $1.794^{* *}$ \\
\hline & $(0.672)$ & $(0.446)$ \\
\hline \multirow[t]{2}{*}{ Moderate decline } & 0.860 & 1.141 \\
\hline & $(0.181)$ & $(0.170)$ \\
\hline \multirow[t]{2}{*}{ Improvement } & 0.961 & 1.006 \\
\hline & $(0.213)$ & $(0.166)$ \\
\hline \multicolumn{3}{|l|}{ Cognitive reserve categories } \\
\hline \multirow[t]{2}{*}{ High positive } & $0.314^{*}$ & 1.240 \\
\hline & $(0.216)$ & $(0.466)$ \\
\hline \multirow[t]{2}{*}{ Moderate positive } & 0.767 & 1.162 \\
\hline & $(0.243)$ & $(0.287)$ \\
\hline \multirow[t]{2}{*}{ Moderate negative } & 1.338 & 1.459 \\
\hline & $(0.373)$ & $(0.345)$ \\
\hline \multirow[t]{2}{*}{ High negative } & 1.230 & $2.086^{* *}$ \\
\hline & $(0.582)$ & $(0.734)$ \\
\hline \multirow[t]{2}{*}{ Number of test taken so far } & 0.970 & $0.898^{*}$ \\
\hline & $(0.096)$ & $(0.056)$ \\
\hline \multirow[t]{2}{*}{ Job tenure between 5 to 15 years } & $0.638^{*}$ & $0.658^{* *}$ \\
\hline & $(0.148)$ & $(0.108)$ \\
\hline \multirow[t]{2}{*}{ Job tenure more than 15 years } & $0.580^{* *}$ & 0.962 \\
\hline & $(0.129)$ & $(0.160)$ \\
\hline \multirow[t]{2}{*}{ New marriage } & 0.866 & 1.496 \\
\hline & $(0.482)$ & $(0.514)$ \\
\hline \multirow[t]{2}{*}{ Newly divorced/widowed } & $1.578^{*}$ & 1.006 \\
\hline & $(0.422)$ & $(0.215)$ \\
\hline \multirow[t]{2}{*}{ Worsening of health } & 1.267 & $1.919 * * *$ \\
\hline & $(0.406)$ & $(0.397)$ \\
\hline \multirow[t]{2}{*}{ Move up wealth quintile } & 1.115 & 1.090 \\
\hline & $(0.220)$ & $(0.150)$ \\
\hline \multirow[t]{2}{*}{ Move down wealth quintile } & $1.553^{*}$ & 1.300 \\
\hline & $(0.367)$ & $(0.229)$ \\
\hline \multirow[t]{2}{*}{ Change in unemployment rate } & 0.932 & $1.941^{* * *}$ \\
\hline & $(0.054)$ & $(0.060)$ \\
\hline Female & 0.960 & 1.075 \\
\hline
\end{tabular}


Table 1. Relative Risk of Downshifting and Retirement (cont'd)

\begin{tabular}{lrr}
\hline & Low cognitive job & Retirement \\
\hline Non-white & 0.874 & 0.864 \\
& $(0.218)$ & $(0.154)$ \\
High School Graduate & 1.142 & 1.231 \\
& $(0.310)$ & $(0.232)$ \\
College and above & 0.818 & 0.964 \\
& $(0.240)$ & $(0.188)$ \\
Blue-collar job & 0.915 & 1.195 \\
& $(0.212)$ & $0.192)$ \\
Risk averse & 1.148 & 0.903 \\
& $(0.213)$ & $(0.120)$ \\
Number of observations & \multicolumn{3}{c}{2,399} \\
Number of individuals & \multicolumn{2}{c}{$1,789^{18}$} \\
\hline
\end{tabular}

Notes: ${ }^{*} \mathrm{p}<0.10,{ }^{* *} \mathrm{p}<0.05,{ }^{* * *} \mathrm{p}<0.01$. Standard errors in parentheses, which is clustered at the individual level. Relative Risk Ratios are reported.

Source: Authors' estimates using Health and Retirement Study 1996-2010 waves.

Table 2: Change in Job Difficulty

\begin{tabular}{|c|c|c|}
\hline & \multicolumn{2}{|c|}{ Job difficulty } \\
\hline & OLS & Probit \\
\hline \multicolumn{3}{|l|}{ Cognitive change categories } \\
\hline Steep decline & $\begin{array}{r}0.037 \\
(0.029)\end{array}$ & $\begin{array}{r}0.038 \\
(0.030)\end{array}$ \\
\hline Moderate decline & $\begin{array}{r}-0.024 \\
(0.016)\end{array}$ & $\begin{array}{r}-0.023 \\
(0.016)\end{array}$ \\
\hline Improvement & $\begin{array}{r}0.025 \\
(0.020)\end{array}$ & $\begin{array}{r}0.025 \\
(0.019)\end{array}$ \\
\hline \multicolumn{3}{|l|}{ Cognitive reserve categories } \\
\hline High positive & $\begin{array}{r}0.002 \\
(0.040)\end{array}$ & $\begin{array}{r}0.002 \\
(0.041)\end{array}$ \\
\hline Moderate positive & $\begin{array}{r}0.009 \\
(0.029)\end{array}$ & $\begin{array}{r}0.008 \\
(0.030)\end{array}$ \\
\hline Moderate negative & $\begin{array}{r}0.022 \\
(0.028)\end{array}$ & $\begin{array}{r}0.020 \\
(0.028)\end{array}$ \\
\hline
\end{tabular}


Table 2: Change in Job Difficulty (cont'd)

\begin{tabular}{|c|c|c|}
\hline & & \\
\hline & OLS & Probit \\
\hline High negative & 0.001 & -0.002 \\
\hline & $(0.043)$ & $(0.045)$ \\
\hline Number of test taken so far & -0.005 & -0.004 \\
\hline & $(0.008)$ & $(0.008)$ \\
\hline Job tenure between 5 to 15 years & $-0.042 * *$ & $-0.040 * *$ \\
\hline & $(0.021)$ & $(0.020)$ \\
\hline Job tenure more than 15 years & $-0.083 * * *$ & $-0.082 * * *$ \\
\hline & $(0.020)$ & $(0.019)$ \\
\hline New marriage & 0.020 & 0.015 \\
\hline & $(0.054)$ & $(0.048)$ \\
\hline Newly divorced/widowed & -0.019 & -0.016 \\
\hline & $(0.025)$ & $(0.026)$ \\
\hline Worsening of health & $0.052^{* *}$ & $0.049 * *$ \\
\hline & $(0.026)$ & $(0.023)$ \\
\hline Move up wealth quintile & $0.035^{* *}$ & $0.036^{* *}$ \\
\hline & $(0.016)$ & $(0.016)$ \\
\hline Move down wealth quintile & 0.030 & 0.031 \\
\hline & $(0.020)$ & $(0.020)$ \\
\hline Change in unemployment rate & 0.002 & 0.002 \\
\hline & $(0.003)$ & $(0.003)$ \\
\hline Female & -0.009 & -0.009 \\
\hline & $(0.017)$ & $(0.017)$ \\
\hline Non-white & -0.003 & -0.003 \\
\hline & $(0.021)$ & $(0.021)$ \\
\hline High School Graduate & $0.073 * * *$ & $0.073^{* * *}$ \\
\hline & $(0.024)$ & $(0.025)$ \\
\hline College and above & $0.045^{*}$ & $0.046 *$ \\
\hline & $(0.024)$ & $(0.025)$ \\
\hline Blue-collar job & 0.019 & 0.018 \\
\hline & $(0.020)$ & $(0.020)$ \\
\hline Risk averse & -0.002 & -0.001 \\
\hline & $(0.017)$ & $(0.016)$ \\
\hline Dummy for remaining in the same job & 0.009 & 0.009 \\
\hline & $(0.016)$ & $(0.016)$ \\
\hline Number of observations & & \\
\hline Number of individuals & & \\
\hline
\end{tabular}

Notes: ${ }^{*} \mathrm{p}<0.10,{ }^{* *} \mathrm{p}<0.05,{ }^{* * *} \mathrm{p}<0.01$. Standard errors, in parentheses, are clustered at the individual level. Average Marginal Effects (AME) are reported for Probit models. Regressions include a full set of base year age dummies. HRS person level weights are used for analysis.

Source: Authors' estimates using Health and Retirement Study, 1996-2010 waves. 
Table 3: Deviation of Actual Retirement Age From Expectation

\begin{tabular}{|c|c|c|}
\hline & All retirements & Excluding voluntary ret \\
\hline \multicolumn{3}{|l|}{ Cognitive change categories } \\
\hline Steep decline & $\begin{array}{l}-2.434^{* * *} \\
(0.473)\end{array}$ & $\begin{array}{l}-3.299^{* * *} \\
(0.873)\end{array}$ \\
\hline Moderate decline & $\begin{array}{r}-0.530 \\
(0.361)\end{array}$ & $\begin{array}{r}-0.808 \\
(0.632)\end{array}$ \\
\hline Improvement & $\begin{array}{l}-1.215^{* * *} \\
(0.383)\end{array}$ & $\begin{array}{r}-0.473 \\
(0.685)\end{array}$ \\
\hline \multicolumn{3}{|l|}{ Cognitive reserve categories } \\
\hline High positive & $\begin{array}{l}-0.780 \\
(0.849)\end{array}$ & $\begin{array}{l}-0.514 \\
(1.422)\end{array}$ \\
\hline Moderate positive & $\begin{array}{r}-0.615 \\
(0.659)\end{array}$ & $\begin{array}{r}-1.648 \\
(1.067)\end{array}$ \\
\hline Moderate negative & $\begin{array}{l}-1.362^{* *} \\
(0.619)\end{array}$ & $\begin{array}{l}-1.393 \\
(1.173)\end{array}$ \\
\hline High negative & $\begin{array}{l}-2.213^{* *} \\
(0.980)\end{array}$ & $\begin{array}{l}-0.711 \\
(1.792)\end{array}$ \\
\hline Number of test taken so far & $\begin{array}{r}-0.219 \\
(0.178)\end{array}$ & $\begin{array}{r}-0.485 \\
(0.308)\end{array}$ \\
\hline Job tenure between 5 to 15 years & $\begin{array}{r}-0.323 \\
(0.430)\end{array}$ & $\begin{array}{r}0.035 \\
(0.711)\end{array}$ \\
\hline Job tenure more than 15 years & $\begin{array}{c}0.803^{*} \\
(0.434)\end{array}$ & $\begin{array}{r}1.092 \\
(0.761)\end{array}$ \\
\hline New marriage & $\begin{array}{l}-2.875^{* * *} \\
(0.920)\end{array}$ & $\begin{array}{l}-2.281 \\
(1.853)\end{array}$ \\
\hline Newly divorced/widowed & $\begin{array}{r}-0.373 \\
(0.509)\end{array}$ & $\begin{array}{r}-0.764 \\
(0.884)\end{array}$ \\
\hline Worsening of health & $\begin{array}{l}-1.808^{* * *} \\
(0.435)\end{array}$ & $\begin{array}{l}-2.773^{* * *} \\
(0.727)\end{array}$ \\
\hline Move up wealth quintile & $\begin{array}{c}-0.538^{*} \\
(0.324)\end{array}$ & $\begin{array}{r}-0.399 \\
(0.581)\end{array}$ \\
\hline Move down wealth quintile & $\begin{array}{r}-0.254 \\
(0.387)\end{array}$ & $\begin{array}{r}-0.416 \\
(0.668)\end{array}$ \\
\hline Change in unemployment rate & $\begin{array}{l}0.143^{* * * *} \\
(0.052)\end{array}$ & $\begin{array}{l}0.400^{* * *} \\
(0.091)\end{array}$ \\
\hline Female & $\begin{array}{l}-0.616^{*} \\
(0.360)\end{array}$ & $\begin{array}{l}-0.666 \\
(0.659)\end{array}$ \\
\hline Non-white & $\begin{array}{c}1.188^{* *} \\
(0.489)\end{array}$ & $\begin{array}{r}-0.072 \\
(0.843)\end{array}$ \\
\hline
\end{tabular}


Table 3: Deviation of Actual Retirement Age From Expectation (cont'd)

\begin{tabular}{lcc}
\hline & All retirements & Excluding voluntary retirements \\
\hline High school graduate & 0.661 & $1.997^{* *}$ \\
College and above & $(0.518)$ & $(0.865)$ \\
& 0.819 & $2.694^{* * *}$ \\
Blue-collar job & $(0.530)$ & $(0.884)$ \\
& $-1.276^{* * *}$ & $-1.644^{* *}$ \\
Risk averse & $(0.408)$ & $(0.699)$ \\
& $0.839^{* *}$ & $2.379^{* * *}$ \\
Number of observations & $(0.344)$ & $(0.613)$ \\
Number of individuals & 4,741 & 2,689 \\
\hline
\end{tabular}

Notes: $* \mathrm{p}<0.10, * * \mathrm{p}<0.05, * * * \mathrm{p}<0.01$. Standard errors in parentheses, which is clustered at the individual level. Regressions include full set of base year age dummies. HRS person level weights are used for analysis.

Source: Authors' estimates using Health and Retirement Study, 1996-2010 waves. 


\section{Appendix C: Outcome Variable Definitions}

\section{Moving to a Job With Low Cognitive Demands}

The beginning and the end waves for measuring job changes are defined by the 10-year window used to measure cognitive decline for each individual. The comparison base wave is the end wave minus one wave. To measure changes in job demands, the cognitive requirement of the job at the base wave is compared to the job at the end wave. If end wave data are missing, job requirements from the end wave plus one wave are used. If that is also missing, job requirements from the end wave plus two waves are used.

\section{Job Difficulty}

The HRS asks: "My job requires me to do more difficult things than it used to. Do you strongly agree, agree, disagree or strongly disagree with that statement?" The response to this question is collapsed into agree and disagree. The question is asked conditional on working. If the respondent is not working at the end wave, the response given at the last wave before retiring is used. To measure whether the subjective job difficulty is higher at the end wave compared to the base wave, the dummy variable is defined that takes the value of 1 if the respondent agrees with the statement at the end wave but disagrees with it at the base wave (and takes a value of 0 otherwise).

\section{Deviation of Actual Retirement Age from Expectation}

Expected retirement age reported at the first wave of the 10-year window is compared to the actual retirement age for this measure. The change variable is defined as actual age minus expected age. Thus, a negative value for this variable indicates that the actual retirement happened earlier than the respondent had expected at the base wave. These observations are uncensored. If the respondent reported "never retire" or "continue as is" to answer the retirement expectation question at the base wave, then we assign 75 as his expected retirement age. Age 75 is chosen as the cut-off age, because few individuals work past this age and robustness checks using 70 as the cut-off age and dropping censored responses altogether do not significantly change the results. These observations are treated as censored observations. If an individual does not retire within the sample period, he is assigned his expected retirement age in the last wave for which data are available regarding the actual retirement age. The rationale for this is 
the literature showing that the expected retirement age close to the actual retirement is a strong predictor of actual retirement (see for example, Bernheim, 1989; Disney and Tanner, 1999;

Loughran et al., 2001). These observations are treated as part of censored observations as well. If in the last observed wave people report "never retire" or "continue as is", then an age of 75 is assigned and the data are also treated as censored observations. 


\section{RECENT WORKING PAPERS FROM THE CENTER FOR RETIREMENT RESEARCH AT BOSTON COLLEGE}

Does Social Security Continue to Favor Couples?

Nadia S. Karamcheva, April Yanyuan Wu, and Alicia H. Munnell, June 2015

Sources of Increasing Differential Mortality Among the Aged by Socioeconomic Status Barry P. Bosworth, Gary Burtless, and Kan Zhang, June 2015

Do Retired Americans Annuitize Too Little? Trends in the Share of Annuitized Income Barry P. Bosworth, Gary Burtless, and Mattan Alalouf, June 2015

Impact of the Financial Crisis on Long-Term Growth

Barry P. Bosworth, June 2015

Post-War Trends in Labor Income in the Social Security Earnings Records Gary Burtless and Kan Zhang, June 2015

Improving Employees' Life and Disability Insurance Benefit Decisions: Results of an Employer Survey

Anek Belbase, Norma B. Coe, and Matthew S. Rutledge, June 2015

Overcoming Barriers to Life Insurance Coverage: A Behavioral Approach

Anek Belbase, Norma B. Coe, and April Yanyuan Wu, June 2015

How Do People Decide on Life Insurance and Long-Term Disability Insurance Coverage? Norma B. Coe and Anek Belbase, June 2015

What Do Subjective Assessments of Financial Well-Being Reflect?

Steven A. Sass, Anek Belbase, Thomas Cooperrider, and Jorge D. Ramos-Mercado, March 2015

The Impact of Leakages from 401(k)s and IRAs

Alicia H. Munnell and Anthony Webb, February 2015

Recruiting and Retaining High-Quality State and Local Workers: Do Pensions Matter? Alicia H. Munnell, Jean-Pierre Aubry, and Geoffrey T. Sanzenbacher, January 2015

Do Tax Incentives Increase 401(k) Retirement Saving? Evidence from the Adoption of Catch-Up Contributions

Matthew S. Rutledge, April Yanyuan Wu, and Francis M. Vitagliano, November 2014

All working papers are available on the Center for Retirement Research website (http://crr.bc.edu) and can be requested by e-mail (crr@bc.edu) or phone (617-552-1762). 